\title{
Expressing Emotions, Resilience and Subjective Well-Being: An Investigation with Structural Equation Modeling
}

\author{
Jale Eldeleklioğlu ${ }^{1} \&$ Meltem Yıldız ${ }^{1}$ \\ ${ }^{1}$ Department of Psychological Counseling and Guidance, Faculty of Education, Bursa Uludag University, Bursa, \\ Turkey
}

Correspondence: Meltem Yıldız, Department of Psychological Counseling and Guidance, Faculty of Education, Bursa Uludag University, Turkey.

Received: October 31, 2019

Accepted: January 16, $2020 \quad$ Online Published: May 24, 2020

doi:10.5539/ies.v13n6p48

URL: https://doi.org/10.5539/ies.v13n6p48

\begin{abstract}
The present study examined the relationship between expressing emotions, psychological resilience and subjective well-being. The study was carried out with a total of 217 university students, of whom 94 were males and 123 were females, aged between 19 and 25 years. The data of the study were collected using the Emotional Expression Questionnaire, the Psychological Resilience Scale and the Subjective Well-Being Scale, respectively. The relationship between the variables of the study was analyzed via the methods of Pearson Correlation Coefficient and Structural Equation Modeling, and the mediating role of psychological resilience between emotional expression and subjective well-being was tested. The goodness-of-fit indices obtained from the structural equation modeling indicated that the model generated a good fit. According to the results, there was a significant relationship between "expressing emotions" and "psychological resilience" and between "psychological resilience" and "subjective well-being". It was found that there was no significant relationship between expressing emotions and subjective well-being and that the variable of expressing emotions affected that of subjective well-being by means of the psychological resilience (tool) variable and the model tested was significant.
\end{abstract}

Keywords: emotional expression, psychological resilience, subjective well-being, structural equation modeling, university students

\section{Introduction}

Subjective well-being is one of the important concepts of positive psychology and makes important contributions to psychological health (Diener \& Seligman, 2004). Subjective well-being consists of individuals' evaluations of their own lives (Diener, 1984; Diener, Suh, \& Oishi, 1997). Three basic components of subjective well-being are expressed as satisfaction with life, a plethora of positive emotions and infrequent unpleasant negative emotions (Diener, 1984; Diener, Suh, Lucas, \& Smith, 1999). Previous studies indicated that individuals with high subjective well-being were more likely to find pleasure in life, lived longer, had happier marriages, were more social, had stronger immune systems and were more successful (Diener \& Seligman, 2002; Lyubomirsky, 2001; Seligman, 2002). Some other studies also showed that subjective well-being was related to heredity and personality characteristics rather than being cultural (Lykken \& Tellegen, 1996), and that such personality characteristics as self-confidence, internal locus of control, optimism, high self-esteem and extroversion were the strongest and most consistent determinants of subjective well-being (Diener, 2000). Other important variable groups affecting subjective well-being were demographic characteristics such as marital status, education level, socio-economic status, age, gender, education, and income level; and personality (extraversion, neuroticism and the characteristics of the goals that individuals have), culture (Diener et al., 1999, 2003; Diener, 2012; Lyubornirsky, 2001; Vera-Villarroel et al., 2012) and activities such as involvement in social relationships, spirituality and fulfilling physical needs (Lyubomirsky, Sheldon, \& Schkade, 2005).

One of the concepts examined and associated with subjective well-being in recent years has been psychological resilience. Psychological resilience is defined as the ability of individuals who are harmed because of traumatic life events to protect their psychological and physical health and recover (Bonanno, 2004; Masten, 2001). Humans are harmed throughout their lives because of such traumatic events as losing loved ones, getting ill, having an accident, going bankrupt, etc. (Bonanno, Brewin, Kaniasty, \& La Greca, 2010). However, most people do not develop pathogenic results and continue their lives when they encounter such traumatic events (Bonanno, 2004; 
Bonanno, Brewin, Kaniasty, \& La Greca, 2010). This phenomenon has been termed as psychological resilience (Bonanno, Westphal, \& Mancini, 2011). Although psychological resilience was initially evaluated as a hereditary characteristic (Jacelon, 1997), the question of why some people suffer less harm when they encounter a trauma depends on many protective factors and hence resilience is a multidimensional concept (Bonanno, 2004). Empirical studies today have revealed the complex interactions between individual and environmental factors that affect the possibility of psychological resilience to difficulty (McEwen, Gray, \& Nasca, 2015). Four factors having protective functions in psychological resilience were summarized as cognitive (optimism, adaptive coping), affective (emotional intelligence), behavioral (adaptive health practices) and environmental (social support) (Curran, Machin, \& Gournay, 2006; de Terte, Becker, \& Stephens, 2009). However, lack of protective factors creates risk factors (Korkut, 2004). There are studies revealing the relationship between protective factors and psychological resilience. For example, family and friend support (Schroevers, Helgeson, Sanderman, \& Ranchor, 2010), external support (Woods, 2005), emotional intelligence (Parker, 2005), optimism and adaptive coping mechanisms (Carver \& Scheier, 2005), adaptive health practices (Buchanan \& Keats, 2011), self-efficacy, being social, and problem solving (Gizir, 2007) are positively related with psychological resilience. Many studies have empirically revealed the interaction of psychological resilience with various positive psychological results, such as psychological adjustment (Arrogante \& Perez-Garcia, 2013) and psychological health (Kashyap, Kumar, \& Krishna, 2014). When the literature is examined, it is observed that psychological resilience is related to both well-being and emotional expression. Recent evidence has revealed that resilience is a strong identifier of subjective well-being (Doyle et al., 2015; Migliorini, Callaway, \& New, 2013; Steptoe, Deraton, \& Stone, 2015). According to the results of Di Fabio and Palazzaechi's (2015) study, on the other hand, the relationship of resilience with subjective well-being was stronger than its relationship with psychological well-being. Furthermore, it was revealed that resilience was positively associated with life satisfaction and positive affect, and negatively associated with negative affect (Hu, Zhang, \& Wang, 2015; Liu, Wang, \& Li, 2012; Liu, Wang, \& Lü, 2013; Lü, Wang, Liu, \& Zhang, 2014; Liu, Wang, Zhou, \& Li, 2014; Mak, Ng, \& Wong, 2011; Singh \& Yu, 2010). For example, Werner and Smith (2001) found that resilient individuals had greater life satisfaction compared with non-resilient ones. Ramanaiah, Sharpe, and Byravan (1999) found in their study, in which they examined the personality characteristics and psychopathologies of resilient and non-resilient individuals, that resilient individuals were more extroverted, open and disciplined. Moreover, the resilient individuals attained significantly lower scores on the neuroticism sub-scale but significantly higher scores on the positive emotion sub-scale. In a study investigating the relationship between psychological resilience and well-being, Fava and Tomba (2009) found that they both increased together. In studies investigating the relationship between psychological resilience and emotional expression, the relationship between positive emotions and psychological resilience was shown clearly (Fredrickson, 2003; Karaırmak \& Çetinkaya, 2011; Tugade \& Fredrickson, 2004). Expressing emotions was at the center of psychological resilience after multiple life events (Armstrong, Galigan, \& Gritchley, 2011).

Emotional expression is the other variable whose relationship with well-being has been investigated. Emotional expression is evaluated as a therapeutic process that lessens the burden of emotional experiences (Rime \& Zech, 2001). At the same time, being able to express emotions is regarded as an important part of psychological and physical health (Pennebaker, 1997). Many psychotherapy and psychological counseling approaches are based on sharing emotions. Recent studies found that emotional expression lessens the effects of traumatic experiences (Hemenover, 2003; Kennedy-Moore \& Watson, 1999). However, when the literature is examined, the results of studies investigating the relationship between subjective well-being and emotional expression indicated that there was no relationship between emotional expression and subjective well-being, contrary to general opinion (Kuzucu, 2006; Rime, 1999; Zech, 1998). The experimental studies by Kuzucu (2006) and Zech (1998) stated that verbally expressing emotions had no effect on subjective well-being. The study by Rime and Zech (2001) stated that sharing emotions socially did not enable emotional relaxation and recovery. However, a study by Flannery (1993) found that children who were supported by their families to express their positive emotions were more popular and congenial and that male children were more flexible and social.

When all of these research results are evaluated, it is understood that there is no clarity on this issue. Based on this, it is also possible to say that testing the mediating effect of psychological resilience in a model by again considering the relationship between emotional expression and subjective well-being will account for an important interaction. The purpose of this study was to suggest a structural model of the relationship between the variables under discussion among university students and investigate whether psychological resilience mediated the relationship between emotional expression and subjective well-being. Based on the purpose of this study, the following hypotheses were tested.

1) There is a positive relationship between emotional expression and psychological resilience. 
2) There is a positive relationship between psychological resilience and subjective well-being.

3) Emotional expression affects subjective well-being with the mediation of psychological resilience.

\section{Method}

\subsection{Participant (Subject) Characteristics}

The study was carried out with a total of 217 students, of whom 94 (43\%) were males and 123 (57\%) were females aged between 19 and 25 years old (with an average of 21.71) from various departments of Uludag University in Turkey.

\subsection{Sampling Procedures}

The sample of the study includes 217 students selected from the students studying in various departments of Uludag University and at various grade levels, and they have been selected with the convenience sampling method.

\subsubsection{Measures}

\subsubsection{Emotional Expression Questionnaire (EEQ)}

In order to determine how much we express our emotions verbally and non-verbally both within and outside of interpersonal relationships, the EEQ (questionnaire) developed by King and Emmons (1990) and adapted to Turkish by Kuzucu was used (2011). The questionnaire is composed of 14 items and three dimensions, namely, closeness, positive emotion and negative emotion. The EEQ is a 7-point Likert-type questionnaire that is scored according to statements ranging from "definitely disagree" (1) to "definitely agree" (7). For the original version of the questionnaire, the reliability coefficient was calculated as .78. In the Turkish version of the questionnaire, the Cronbach's alpha internal consistency coefficient was .85 , and the test-retest reliability coefficient applied at an interval of three weeks was found to be .85 . For criterion-related validity, it was found that there was positive correlation with the Psychological Well-Being Questionnaire (Kuzucu, 2011).

\subsubsection{Resilience Scale for Adults (RSA)}

In order to assess adults' psychological resilience, the Resilience Scale for Adults developed by Friborg, Barlaug, Martinussen, Rosevinge, and Hiemdal (2005) and adapted to Turkish by Basım and Çetin (2011) was used. The scale is composed of 33 items and six dimensions, namely, perception of self, planned future, structural style, social competence, family coherence, and social support. The answers are organized as five boxes to eliminate acquiescence bias and evaluated as if they were on a 5-point Likert scale (1 never, 5 always). In the original version of the scale, the total Cronbach's alpha coefficient was calculated as .86. For the sub-dimensions, the Cronbach's alpha coefficients varied from .66 to .81 . In the Turkish version of the scale, it was found that the Cronbach's alpha internal consistency coefficients varied from .66 to .81 and that the test-retest reliability coefficient varied from .66 to .81 . As a result of the factor analysis, a six-factor structure of the scale, which corresponds with the original version, was verified (Basım \& Çetin, 2011).

\subsubsection{Subjective Well-Being Scale (SWB)}

In order to determine individuals' cognitive evaluations about their own lives and the frequency of their positive and negative emotions, the Subjective Well-Being Scale developed by Tuzgöl-Dost (2005) was used. The scale is a Likert-type scale composed of a total of 46 items: 26 positive and 20 negative. The answers are scored from completely appropriate (5) to never appropriate (1). The scale has 12 factors, namely, comparison, emotions, goals, self-confidence, optimism, activities, friendship relations, looking to the future, family relations, envy, coping, and pessimism, and it is also accepted to have a general factor. It was found that the Cronbach's alpha coefficient of the SWB scale was .93, and the test-retest consistency coefficient was .86 (Tuzgöl-Dost, 2005).

\subsubsection{Procedure and Data Analysis}

The self-report measures were administered by the researcher to the students within lesson hours in one session. The students were informed about the aim of the study and were given explanations about how to fill in the scales. The scales were subsequently given only to the students who volunteered. The participants answered the questionnaires in approximately 20 minutes. The relationship between the variables of the study was calculated through the Pearson product-moment correlation coefficient in the SPSS 20 statistical analysis program. The effects of emotional expression and psychological resilience on subjective well-being were tested using the structural equation model in LISREL 8.50. For the structural equation model analysis, the latent and observed variables in the model were first expressed, as shown in the table below.

The questions on each scale and sub-scale shown in the above table were not given so as to prevent confusion. The 
questions belonging to the observed variables were arranged in accordance with the scale instructions (recoding of reverse questions). Their means were then calculated, and a single factor score for each sub-factor was formed for each subject.

Table 1. Latent and observed variables included in the structural equation model

\begin{tabular}{lcc}
\hline Latent Variables & Observed Variables (Sub-Factors) & Abbreviations* \\
\hline \multirow{3}{*}{ Emotional Expression } & Positive Emotion & $\mathrm{P}$ \\
& Negative Emotion & $\mathrm{N}$ \\
& Closeness & $\mathrm{C}$ \\
& Perception of self & $\mathrm{PS}$ \\
Psychological resilience & Planned future & $\mathrm{PF}$ \\
& Structural style & $\mathrm{S}$ \\
& Social Competence & $\mathrm{SCO}$ \\
& Family Coherence & $\mathrm{FC}$ \\
& Social Support & $\mathrm{SS}$ \\
& Comparison & $\mathrm{C}$ \\
& Emotions & $\mathrm{E}$ \\
& Goals & $\mathrm{G}$ \\
& Self-Confidence & $\mathrm{SC}$ \\
& Optimism & $\mathrm{O}$ \\
& Activities & $\mathrm{A}$ \\
& Friendship Relations & FR \\
& Looking to Future & LF \\
& Family Relations & FR \\
& Envying & E \\
& Coping & $\mathrm{C}$ \\
& Pessimism & $\mathrm{P}$ \\
\hline
\end{tabular}

\section{Results}

In the present study, confirmatory factor analysis was performed, and the measurement model was examined, and then the correlation coefficients between the variables included in the model were calculated. The structural equation model was then examined.

\subsection{Confirmatory Factor Analysis}

When the goodness-of-fit indices obtained from the first confirmatory factor analysis were examined, it was observed that the $\chi^{2} / \mathrm{Sd}$ and RMSEA values did not show a sufficient fit (Hu \& Bentler, 1999; Kline, 2005). It was determined that the $t$ values expressing the significant factor coefficients of the negative emotion (N) sub-factor of emotional expression and the envy (E) factor of subjective well-being were not statistically significant, and for this reason, they were excluded from the model. When the correction indices were examined, it was determined that the exclusion of the social competence (SC) sub-factor of psychological resilience and the positive and negative emotions (E), goals (G), family relations (FR), looking to the future (LF) and coping with difficulties (C) sub-factors of subjective well-being would contribute to the goodness-of-fit of the model, and for this reason, they were excluded from the model. After excluding these variables from the model, the confirmatory factor analysis was repeated, and it was observed that the model had a very good fit as a result of the obtained goodness-of-fit indices. Information about the goodness-of-fit indices is shown in Table 2.

Table 2. Goodness-of-fit values obtained as a result of factor analysis*

\begin{tabular}{cccc}
\hline Goodness of fit indices & Levels of perfect fit & Levels of acceptable fit & Calculated fit indices \\
\hline$\chi^{2} / \mathrm{Sd}$ & $0<\chi^{2} / \mathrm{Sd}<2$ & $2<\chi^{2} / \mathrm{Sd}<3$ & 1.39 \\
RMSEA & $.00<\mathrm{RMSEA}<.05$ & $.05<\mathrm{RMSEA}<.08$ & .043 \\
SRMR & $.00<\mathrm{RMR}<.05$ & $.05<\mathrm{RMR}<.10$ & .043 \\
TLI (NNFI) & $.95<\mathrm{TLI}<1.00$ & $.90<\mathrm{TLI}<.95$ & .98 \\
CFI & $.95<\mathrm{CFI}<1.00$ & $.90<\mathrm{CFI}<.95$ & .99 \\
\hline
\end{tabular}

*Resources: Hu and Bentler (1999), Kline (2005). 
After determining that the model had a good fit, the factor loadings indicating whether the sub-factors were related to their conceptual structures were examined. It was observed that all of the factor loadings were statistically significant. The measurement models for the subjective well-being, psychological resilience and emotional expression scales are shown in Figure 1.

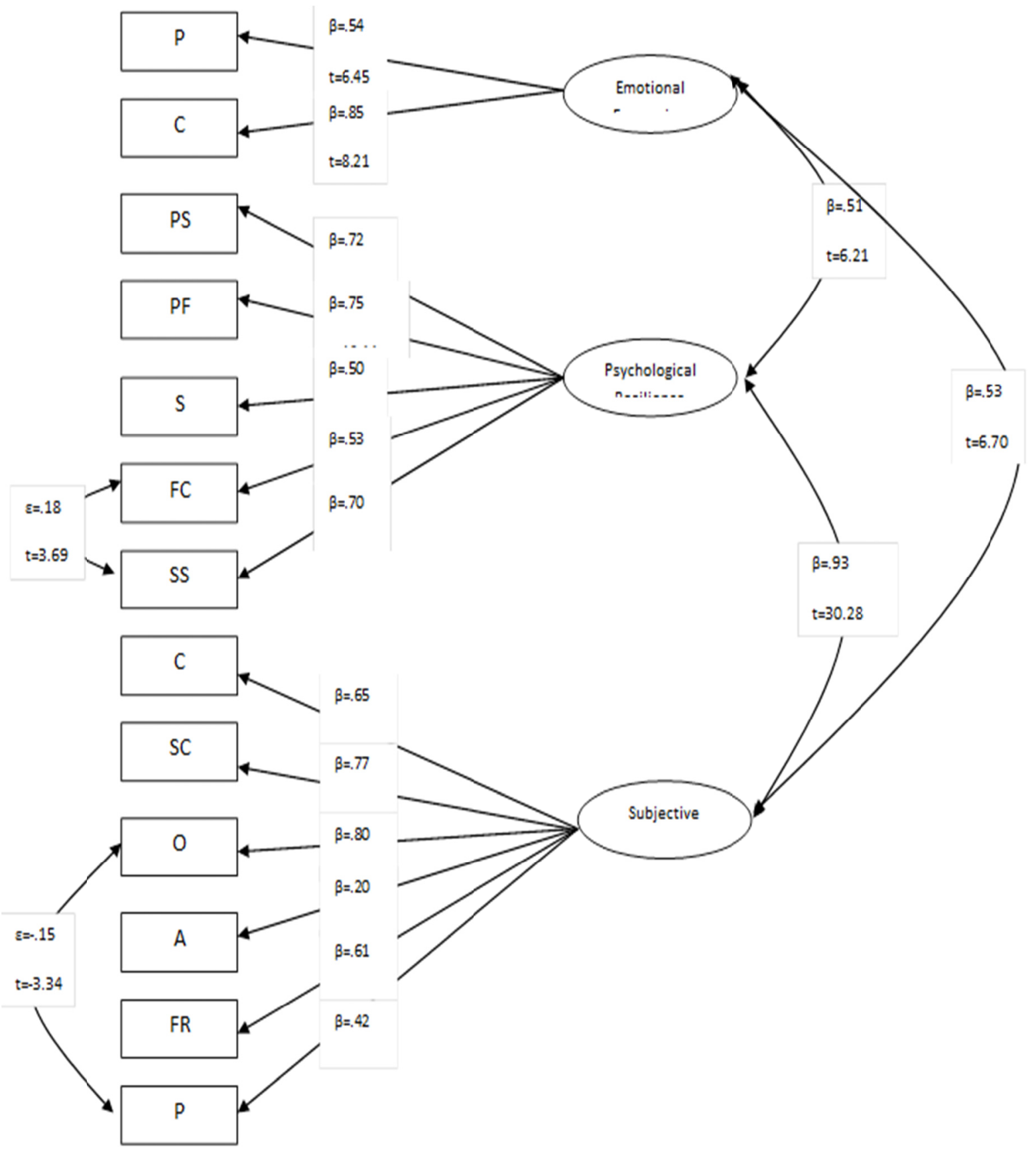

Figure 1. Measurement models of emotional expression, psychological resilience and subjective well-being

When the standardized factor loading coefficients were examined, it was observed that the "closeness" variable was the best representative of emotional expression, the "planned future" variable was the best representative of psychological resilience and the "optimism" variable was the best representative of subjective well-being.

\subsection{Correlation Coefficients Between the Variables}

Based on the hypotheses of the study, initially as a result of the first confirmatory factor analysis, the correlation 
coefficients between the variables included in the model were calculated through the Pearson product-moment correlation test. It was found that the positive emotion sub-dimension of emotional expression was positively related with the perception of self $(p<.05)$, planned future $(p<.001)$ and family coherence $(p<.05)$ sub-dimensions of psychological resilience, but negatively related with social resources $(\mathrm{p}<.01)$. Moreover, it was found that positive emotion was positively related with the perception of self $(p<.01)$ and optimism $(p<.01)$ sub-dimensions of subjective well-being. It was also found that closeness, another sub-dimension of emotional expression, was positively related with perception of self, planned future, structural style and family coherence $(\mathrm{p}<.01)$ but negatively related with social support $(\mathrm{p}<.01)$. A positive relationship was found between closeness and the self-confidence, optimism and friendship relations sub-dimensions of subjective well-being $(p<.01)$. It was found that the perception of self, planned future, structural style and family coherence sub-dimensions of psychological resilience were positively related with the comparing oneself with others, self-confidence, optimism, friendship relationship and pessimism $(\mathrm{p}<.01)$ sub-dimensions of subjective well-being, but that the social support sub-dimension of psychological resilience was negatively related with the comparison, self-confidence, optimism, activities of interest, friendship relations and pessimism sub-dimensions of subjective well-being $(\mathrm{p}<.01)$.

\subsection{Analysis of Structural Equation Modeling}

After evaluating the model's factor structure in the first stage and establishing that the model's goodness-of-fit was statistically sufficient, the structural equation model in which the hypotheses defined at the beginning would be evaluated was analyzed. The goodness-of-fit values related to the model are given in Table 3 .

Table 3. Goodness-of-fit values

\begin{tabular}{cccc}
\hline Goodness of fit indices & Levels of perfect fit & Levels of acceptable fit & Calculated fit indices \\
\hline$\chi^{2} / \mathrm{Sd}$ & $0<\chi^{2} / \mathrm{Sd}<2$ & $2<\chi^{2} / \mathrm{Sd}<3$ & 1.57 \\
RMSEA & $.00<\mathrm{RMSEA}<.05$ & $.05<\mathrm{RMSEA}<.08$ & .051 \\
SRMR & $.00<\mathrm{RMR}<.05$ & $.05<\mathrm{RMR}<.10$ & .050 \\
TLI (NNFI) & $.95<\mathrm{TLI}<1.00$ & $.90<\mathrm{TLI}<.95$ & .97 \\
CFI & $.95<\mathrm{CFI}<1.00$ & $.90<\mathrm{CFI}<.95$ & .98 \\
\hline
\end{tabular}

When the goodness-of-fit values in Table 3 were examined, it was observed that the model had a perfect fit. Since the structural equation model had a good fit, the significance of each factor loading coefficient belonging to the model was tested. When the $t$ values of the factor loading coefficients belonging to the one-way relationship between the latent variables included in the diagram in Figure 2 were examined, it was observed that none of the values remained below the critical value of 1.96 , but they were on the high side $(\mathrm{p}<.05)$. In the model shown in Figure 2, the structural equation model in which psychological resilience was a complete mediator was tested. In other words, in this model, the structural equation model in which emotional expression affected subjective well-being more than psychological resilience was tested. The standardized factor loading coefficients belonging to the relationship included in the structural equation model indicated that there was a significant positive relationship between the latent "emotional expression" variables and the latent "psychological resilience" variables at a moderate level $(\mathrm{p}<.01)$ and that there was a significant positive relationship between the latent "psychological resilience" variables and the latent "subjective well-being" variables at a high level $(\mathrm{p}<.01)$. Whether the variable emotional expression directly affected the variable subjective well-being was examined, as shown in Figure 3. It was observed that the direct relationship between emotional expression and subjective well-being added to the model in Figure 3 was not significant ( $>$.05). For this reason, there was no need to add this relationship to the structural equation model. Moreover, adding this relationship to the structural equation model did not lead to a significant increase in the chi-square difference value $\left(\Delta \chi^{2}=2.26, p>.05\right)$. In sum, there was a significant relationship between emotional expression and psychological resilience $(p<.05)$ and between psychological resilience and subjective well-being $(\mathrm{p}<.05)$, but there was not a significant relationship between emotional expression and subjective well-being ( $>$.05). The Sobel test revealed that the mediation effect was significant $(\mathrm{z}=4.997, \mathrm{p}<.01)$. 


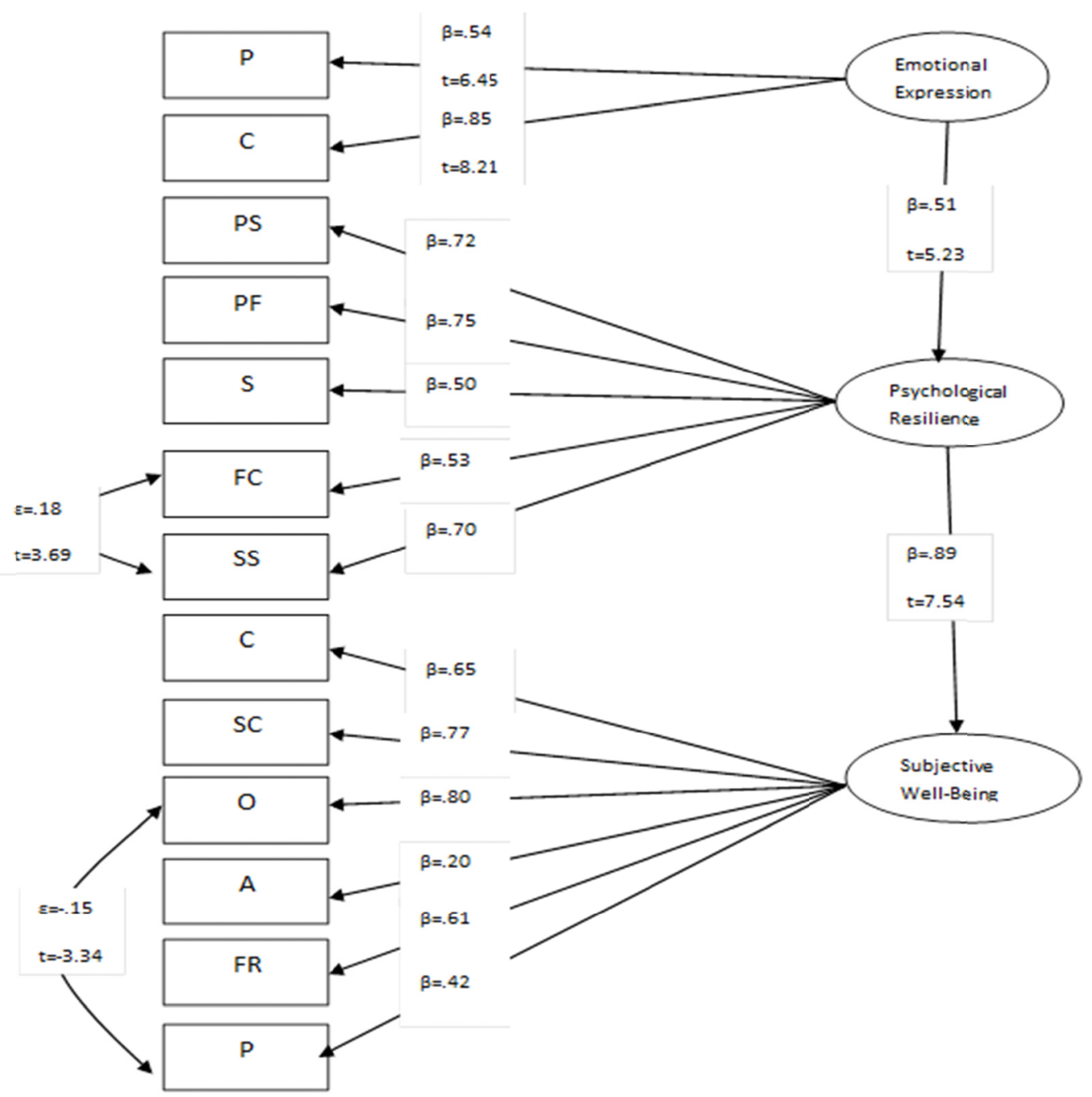

Figure 2. Standardized coefficients and the $t$ values of the structural equation model 


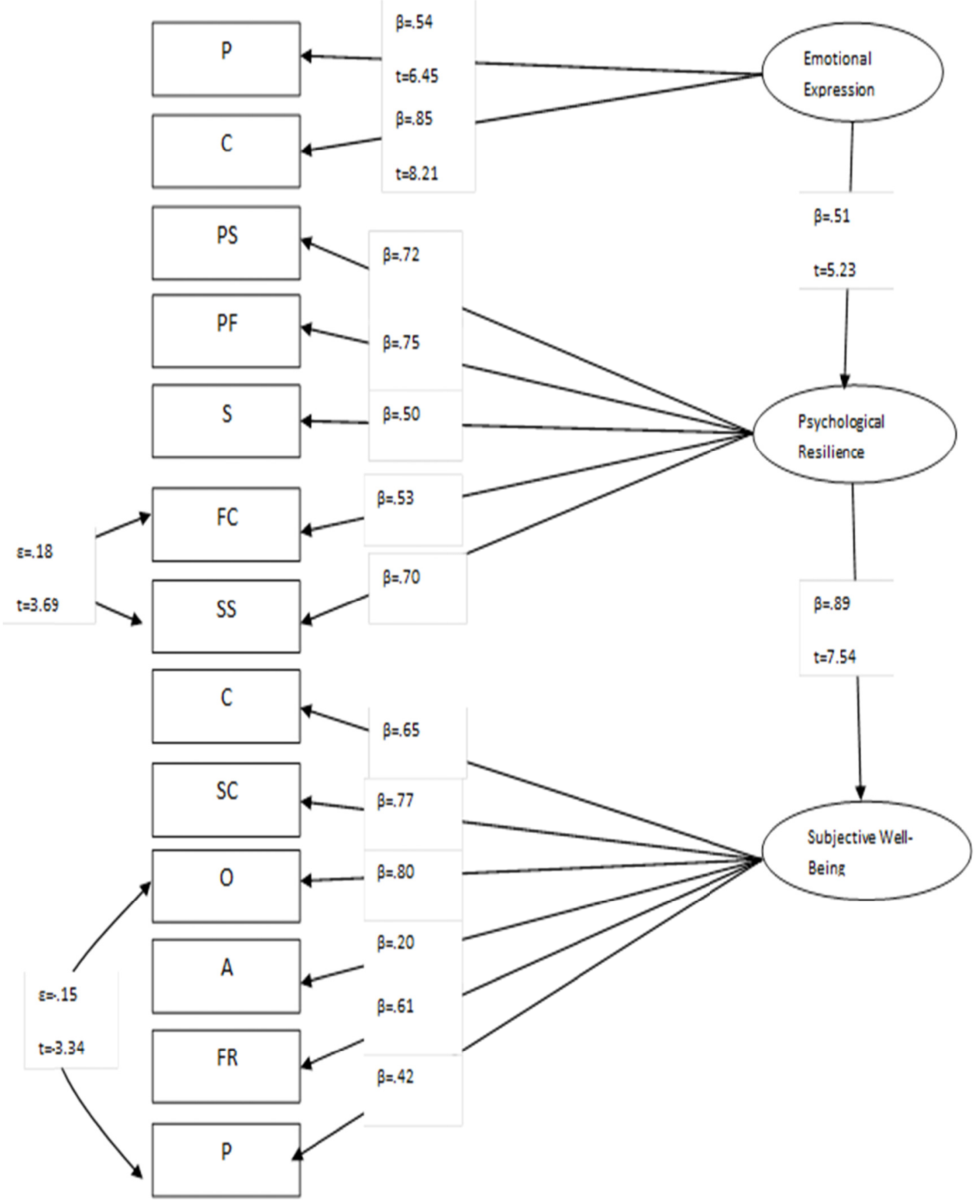

Figure 3. Standardized coefficients and $t$ values of the structural model

\section{Discussion}

When the relevant literature was examined, it was observed that since it was a relatively new subject, there were few studies indicating the relationship between psychological resilience and subjective well-being. Therefore, the purpose of this study was to put forward a structural model of the relationship between psychological resilience, expressing emotions and subjective well-being and to examine if psychological resilience mediated the relationship between expressing emotions and subjective well-being. For this purpose, the relationships between expressing emotions, psychological resilience and subjective well-being were examined by using correlation analysis, and the mediating role of psychological resilience between expressing emotions and subjective well-being was examined using structural equation modelling. The research results showed significant relationships between expressing emotions and psychological resilience and subjective well-being. At the same 
time, the research findings showed that the variable of expressing emotions affected the variable of subjective well-being via the variable of psychological resilience; that is to say, the tested model was verified statistically. According to the verified model, the relationship between expressing emotions and subjective well-being was realized via full mediation of psychological resilience.

Firstly, it was observed that positive emotions and closeness, which were the sub-dimensions of expressing emotions, predicted perception of self, perception of future, structural style, and family coherence, which were the sub-dimensions of psychological resilience in the positive direction. This result partially verified the assumption that "There is a positive relationship between expressing emotions and psychological resilience", which was the first hypothesis of the study. This finding shows consistency with some research findings obtained in recent studies on expressing emotions and psychological flexibility. According to the results of Vaugh, Thompson \& Gotlib's (2011) study, people with high resilience are better at expressing their emotional experiences openly through their facial expressions than those who have low resilience. According to Huston, Blount, Heidesch and Southwood (2016), on the other hand, there is a positive relationship between expressing one's feelings to one's friends, but not to one's families, and acquiring direct benefits (this can be defined as a positive psychological change due to a difficult negative experience or time period in life, or finding meaning in sad situations, and goes beyond resilience to include personal growth). In the studies carried out by Fredrickson (2001, 2003), Karairmak and Çetinkaya (2011), and Tugade and Fredrickson (2004), the relationship between positive emotions and psychological resilience was clearly revealed. In two extensive meta-analyses, it was concluded from both experimental and longitudinal studies that positive emotions were not only derived from, but also preceded enhanced success and physical and mental health (Lyubomirsky, King, \& Diener, 2005; Pressman \& Cohen, 2005).

Secondly, when the relationship between psychological resilience and subjective well-being was examined, it was observed that the variable of psychological resilience (the variables of perception of self, perception of future, structural style, and family coherence) predicted the comparison, self-confidence, optimism, activities, friendship relations and pessimism sub-dimensions of subjective well-being in the positive direction and that the social support sub-dimension predicted the same variables in the negative direction. Hence, the assumption that "there is a significant relationship between psychological resilience and subjective well-being", which was the second hypothesis of the study, was partially verified. Moreover, there are some study findings showing parallelism with those of the present study. Previous studies proved that there was a positive relationship between subjective well-being and resilience (Di Fabio \& Palazzaechi, 2015; Kirmani, Sharma, Anas, \& Sanam, 2015; Mahmood \& Ghaffar, 2014; Seller, 2016; Yıldırım \& Belen, 2019; Zubair, Kamal, \& Artemena, 2018). For example, Fava and Tomba (2009) determined that psychological resilience and subjective well-being increased together. In a study, Werner and Smith (2001) found that resilient individuals had higher life satisfaction than non-resilient ones.

Consequently, it was observed in the established model that the variable of expressing emotions affected the variable of subjective well-being via the variable of psychological resilience. A pragmatic explanation for the buffering role of resilience in predicting subjective well-being was made by Ifeagwazi et al. (2015) and Kashyap et al. (2014). Accordingly, resilience skills help individuals manage negative effects (such as psychological distress and varying levels of personal and professional stress) and thus lead to positive results (such as improved psychological health, and positive spiritual and subjective well-being) (Zubair, Kamal, \& Artemena, 2018). When the situation in which the variable of expressing emotions directly affected the variable of subjective well-being was evaluated, it was observed that this relationship was not significant and therefore, was not included in the model. For this reason, the hypothesis that psychological resilience was the mediating variable between expressing emotions and subjective well-being was supported. This finding shows parallelism with some findings in the literature. As a result of their structural equality model analysis, Yıldırım and Belen (2019) revealed that resilience partially mediated the relationships between the externality of happiness and subjective well-being and development. However, in an experimental study carried out by Kuzucu (2006), the effect of a psycho-training program prepared with the aim of helping individuals to notice and express emotions on emotional and subjective well-being was investigated, and it was found that the training of expressing emotions did not improve subjective well-being. Besides this, there are also other studies indicating that expressing emotions has nothing to do with subjective well-being (van Emmerik, Kamphuis, Hulbosch, \& Emmelkamp, 2002; Zech, 1998).

Similar to other studies, this study also has some limitations. Firstly, since the study was carried out with university students, the generalizability of the results is limited. The study can be replicated with more varied sample groups. Secondly, the study examined the relationship between expressing emotions, psychological resilience and subjective well-being, and the mediating role of psychological resilience. In similar studies, alternative models can be tried, and research findings can become stronger. Thirdly, the results obtained from this study are limited to the self-reported answers given by the participants. Finally, this study was carried out according to the structural 
equation model (even though the structural equation modeling suggests results related to causality, it is difficult to give a full explanation related to causality among the variables examined in the research, as correlational data were used).

In this study, it was found that expressing emotions was not directly related with subjective well-being and that expressing emotions affected subjective well-being via the mediation of psychological resilience. At this point, it is observed that psychological resilience plays an important role in subjective well-being, that is, in individuals' happiness. It is an expected result that individuals with higher strength to recover and be flexible in the face of traumatic life experiences feel better.

\section{References}

Armstrong, A. R., Galligan, R. F., \& Critchley, C. R. (2011). Emotional intelligence and psychological resilience to negative life events. Personality and Individual Differences, 51(3), 331-336. https://doi.org/10.1016/j.paid.2011.03.025

Arrogante, O., \& Perez-Garcia, A. M. (2013). Is subjective well-being perceived by non-health care workers different from that perceived by nurses? Relation with Personality and Resilience, 24(4), 145-154. https://doi.org/10.1016/j.enfi.2013.07.002

Basım, N. H., \& Çetin, F. (2011). The reliability and validity of the resilience scale for adults. Turkish Journal of Psychiatry, 22(2), 104-114. Retrieved from https://www.researchgate.net/publication/51188618_The Reliability_and_Validity_of_the_Resilience_Scale_for_Adults-Turkish_Version

Bonanno, G. A. (2004). Loss, trauma, and human resilience: Have we underestimated the human capacity to thrive after extremely aversive events? American Psychologist, 59, 20-28. https://doi.org/10.1037/0003-066X.59.1.20

Bonanno, G. A., Brewin, C. R., Kaniasty, K., \& Greca, A. M. L. (2010). Weighing the costs of disaster: Consequences, risks, and resilience in individuals, families, and communities. Psychological science in the public interest, 11(1), 1-49. https://doi.org/10.1177/1529100610387086

Bonanno, G. A., Westphal, M., \& Mancini, A. D. (2011). Resilience to loss and potential trauma. Annual Review of Clinical Psychology, 7, 511-535. https://doi.org/10.1146/annurev-clinpsy-032210-104526

Buchanan, M., \& Keats, P. (2011). Coping with traumatic stress in journalism: A critical ethnographic study. International Journal of Psychology, 46(2), 127-135. https://doi.org/10.1080/00207594.2010.532799

Carver, C. S., \& Scheier, M. F. (2005). Optimism. In C. R. Snyder, \& S. J. Lopez, (Eds.) Handbook of positive psychology (pp. 231-243). New York: Oxford University Press.

Curran, J., Machin, C., \& Gournay, K. (2006). Cognitive behavioral therapy for patients with anxiety and depression. Nursing Standard, 21(7), 44-52. https://doi.org/10.7748/ns.21.7.44.s49

De Terte, I., Becker, J., \& Stephens, C. (2009). An integrated model for understanding and developing resilience in the face of adverse events. Journal of Pacific Rim Psychology, 3, $20-26$. https://doi.org/10.1375/prp.3.1.20

Di Fabio, A., \& Palazzeschi, L. (2015). Hedonic and eudaimonic well being: the role of resilience beyond fluid intelligence and personality traits. Frontiers in Psychology, 6, 1-7. https://doi.org/10.3389/fpsyg.2015.01367

Diener, E. (1984). Subjective well-being. Psychological Bulletin, 95, $542-575$. https://doi.org/10.1037/0033-2909.95.3.542

Diener, E. (2000). Subjective well-being: The science of happiness and a proposal for a national index. American psychologist, 55(1), 34-43. https://doi.org/10.1037/0003-066X.55.1.34

Diener, E. (2012). New findings and future directions for subjective well-being research. American Psychologist, 67(8), 590-597. https://doi.org/10.1037/a0029541

Diener, E., \& Seligman, M. E. (2002). Very happy people. Psychological Science, 13, 81-84. https://doi.org/10.1111/1467-9280.00415

Diener, E., \& Seligman, M. E. (2004). Beyond money: Toward an economy of well-being. Psychological Science in the Public Interest, 5(1), 1-31. https://doi.org/10.1111/j.0963-7214.2004.00501001.x

Diener, E., Oishi, S., \& Lucas, R. E. (2003). Personality, culture, and subjective well-being: Emotional and cognitive evaluations of life. Annual Review of Psychology, 54, 403-425. 
https://doi.org/10.1146/annurev.psych.54.101601.145056

Diener, E., Suh, E. M., \& Oishi, S. (1997). Recent findings on subjective well-being. Indian Clinical Psychology, 24, 25-41. Retrieved from https://intranet.newriver.edu/images/stories/library/Stennett_Psychology_Articles /Recent\%20Findings\%20on\%20Subjective\%20Well-Being.pdf

Diener, E., Suh, E. M., Lucas, R. E., \& Smith H. L. (1999). Subjective well-being: Three decades of progress. Psychological Bulletin, 125(2), 276-302. https://doi.org/10.1037/0033-2909.125.2.276

Doyle, N., MacLachlan, M., Fraser, A., Stilz, R., Lismont, K., Cox, H., \& McVeigh, J. (2015). Resilience and well-being amongst seafarers: cross-sectional study of crew across 51 ships. International Archives of Occupational and Environmental Health (pp. 1-11). https://doi.org/10.1007/s00420-015-1063-9

Fava, G. A., \& Tomba, E. (2009). Increasing psychological well - being and resilience by psychotherapeutic methods. Journal of personality, 77(6), 1903-1934. https://doi.org/10.1111/j.1467-6494.2009.00604.x

Flannery, D. J. (1993). Affective expression and emotion in early adolescence: An introduction. Journal of Early Adolescence, 13(4), 356-360. https://doi.org/10.1177/0272431693013004001

Fredrickson, B. L. (2001). The role of positive emotions in positive psychology: The broaden-and-build theory of positive emotions. American Psychologist, 56, 218-226. https://doi.org/10.1037/0003-066X.56.3.218

Fredrickson, B. L. (2003). The value of positive emotions. American Scientist, 91(4), 330-335. https://doi.org/10.1511/2003.4.330

Friborg, O, Barlaug, D, Martinussen, M., Rosevinge, J. H., \& Hiemdal, O. (2005). Resilience in relation to personality and intelligence. International Journal Methods in Psychiatric Research, 4(1), 29-42. https://doi.org/10.1002/mpr.15

Gizir. C. A. (2007). A Literature review of studies on resilience, risk, and protective factors. Turkish Psychological Counseling and Guidance Journal, 3(28), 113-128. Retrieved from http://dergipark.gov.tr/tpdrd/issue/21448/229850

Hemenover, S. H. (2003). The good, the bad, and the healthy: Impacts of emotional disclosure of trauma on resilient self-concept and psychological distress. Personality and Social Psychology Bulletin, 23(10), 1236-1244. https://doi.org/10.1177/0146167203255228

https://doi.org/10.1093/occmed/kqi085

Hu, L., \& Bentler, P. (1999). Cut off criteria for fit indexes in covariance structure analysis: Conventional criteria versus new alternatives. Structural Equation Modeling, 6(1), 1-55. https://doi.org/10.1080/10705519909540118

Hu, T., Zhang, D., \& Wang, J. (2015). A meta-analysis of the trait resilience and mental health. Personality and Individual Differences, 76, 18-27. https://doi.org/10.1016/j.paid.2014.11.039

Huston, S. A., Blount, R. L., Heidesch, T., \& Southwood, R. (2016). Resilience, emotion processing and emotion expression among youth with type 1 diabetes. Pediatric Diabetes, 17, 623-631. https://doi.org/10.1111/pedi.12347

Ifeagwazi, C. M., Chukwuorji, J. B. C., \& Zacchaeus, E. (2015). Alienation and psychological wellbeing: Moderation by resilience. Social Indicators Research, 120(2). https://doi.org/10.1007/s11205-014-0602-1

Jacelon, C. S. (1997). The trait and process of resilience. Journal of Advanced Nursing, 25, 123-129. https://doi.org/10.1046/j.1365-2648.1997.1997025123.x

Karaırmak, Ö., \& Çetinkaya, R. Ş. (2011). The effect of self-esteem and locus of control on resilience: The mediating role of affects. Turkish Psychological Counseling and Guidance Journal, 4(35), 30-43. Retrieved from: http://dergipark.gov.tr/tpdrd/issue/21455/229666

Kashyap, S. P., Kumar, S., \& Krishna, A. (2014). Role of resilience as a moderator between the relationship of occupational stress and psychological health. Indian Journal of Health and Wellbeing, 5(9), 1023-1026. Retrieved from https://www.researchgate.net/profile/Sandeep_Kumar144/publication/271139299_Role_of_ resilience_as_a_moderator_between_the relationship_of_occupational_stress_and_psychological_health/li nks/54eca 7 d 60 cf $2465 f 532$ fdaab/Role-of-resilience-as-a-moderator-between-the-relationship-of-occupationa 1-stress-and-psychological-health.pdf

Kennedy-Moore, E., \& Watson, J. C. (2001). Expressing emotion: Myths, realities, and therapeutic strategies. Guilford Press. 
King, L. A., \& Emmons, R., A. (1990). Conflict over emotional expression: Psychological and physical correlates. Journal of Personality and Social Psychology, 58(5), 64-87. https://doi.org/10.1037/0022-3514.58.5.864

Kirmani, M. N., Sharma, P., Anas, M., \& Sanam, R.(2015). Hope, resilience and subjective well-being among college going adolescent girls. International Journal of Humanities \& Social Science Studies, 2(1), 262-270. Retrieved from http://oaji.net/articles/2015/1115-1438581068.pdf

Kline, R. B. (2005). Principles and practice of structural equation modeling (2nd ed.). New York: Guilford.

Korkut, F. (2004). School-based preventive guidance and psychological counseling. Ankara, Anı Publishing.

Kuzucu, Y. (2006). Duygularl fark etmeye ve ifade etmeye yönelik bir psiko-eğitim programının üniversite ögrencilerinin duygusal farkindalı düzeylerine, duyguları ifade etme eğilimlerine, psikolojik ve öznel iyi oluşlarına etkisi (Doctoral thesis). Available from Council of Higher Education Thesis Center (Thesis No. 205150)

Kuzucu, Y. (2011). Adaptation of the emotional expression questionnaire: Validity and reliability studies. Kastamonu Education Journal, 9(3), 779-792. Retrieved from: https://toad.edam.com.tr/sites/default/files/pdf/duygulari-ifade-etme-toad.pdf

Liu, Y., Wang, Z. H., \& Li, Z. G. (2012). Affective mediators of the influence of neuroticism and resilience on life satisfaction. Personality and Individual Differences, 52, 833-838. https://doi.org/10.1016/j.paid.2012.01.017

Liu, Y., Wang, Z., \& Lü, W. (2013). Resilience and affect balance as mediators between trait emotional intelligence and life satisfaction. Personality and Individual Differences, 54(7), 850-855. https://doi.org/10.1016/j.paid.2012.12.010

Liu, Y., Wang, Z., Zhou, C., \& Li, T. (2014). Affect and self-esteem as mediators between trait resilience and psychological adjustment. Personality and Individual Differences, 66, 92-97. https://doi.org/10.1016/j.paid.2014.03.023

Lü, W., Wang, Z., Liu, Y., \& Zhang, H. (2014). Resilience as a mediator between extraversion, neuroticism and happiness, PA and NA. Personality and Individual Differences, 63, 128-133. https://doi.org/10.1016/j.paid.2014.01.015

Lykken, D., \& Tellegen, A. (1996). Happiness is a stochastic phenomenon. Psychological Science, 7, 186-189. https://doi.org/10.1111/j.1467-9280.1996.tb00355.x

Lyubomirsky, S. (2001). Why are some people happier than others? The role of cognitive and motivational $\begin{array}{llll}\text { processes in well-being. American } & \text { 239-249. }\end{array}$ https://doi.org/10.1037/0003-066X.56.3.239

Lyubomirsky, S., King, L., \& Diener, E. (2005). The benefits of frequent positive affect: Does happiness lead to success? Psychological bulletin, 131, 803-855. https://doi.org/10.1037/0033-2909.131.6.803

Lyubomirsky, S., Sheldon, K. M., \& Schkade, D. (2005). Pursuing happiness: The architecture of sustainable change. Review of General Psychology, 9, 111-131. https://doi.org/10.1037/1089-2680.9.2.111

Mahmood, K., \& Ghaffar, A. (2014). The relationship between resilience, psychological distress and subjective well-being among dengue fever survivors. Global Journal of Human-Social Science: An Arts \& Humanities-Psychology, 14(10), 12-20. Retrieved https://pdfs.semanticscholar.org/6b96/5f348be30d145f2873f0af9f997c9c346fd8.pdf

Mak, W. W. S., Ng, I. S. W., \& Wong, C. C. Y. (2011). Resilience: Enhancing well-being through the positive cognitive triad. Journal of Counseling Psychology, 58(4), 610-617. https://doi.org/10.1037/a0025195

Masten, A. S. (2001). Ordinary magic. Resilience processes in development. American Psychologist, 56(3), 227-238. https://doi.org/10.1037/0003-066X.56.3.227

McEwen, B. S., Gray, J. D., \& Nasca, C. (2015). Recognizing resilience: Learning from the effects of stress on the brain. Neurobiology of Stress, 1(1), 1-11. https://doi.org/10.1016/j.ynstr.2014.09.001

Migliorini, C., Callaway, L., \& New, P. (2013). Preliminary investigation into subjective well-being, mental health, resilience, and spinal cord injury. The Journal of Spinal Cord Medicine, 36(6), 660-665. https://doi.org/10.1179/2045772313Y.0000000100

Parker, J. D. A. (2005). Relevance of emotional intelligence for clinical psychology. In R. Schulze, \& R. D. 
Roberts (Eds.), International handbook of emotional intelligence (pp. 271-287). Berlin: Hogrefe \& Huber.

Pennebaker, J. W. (1997). Writing about emotional experiences as a therapeutic process. Psychological Science, 8, 162. https://doi.org/10.1111/j.1467-9280.1997.tb00403.x

Pressman, S. D., \& Cohen, S. (2005). Does positive affect influence health? Psychological Bulletin, 131(6), 925-971. https://doi.org/10.1037/0033-2909.131.6.925

Ramanaiah, N. V., Sharp, J. P., \& Byravan, A. (1999). Hardiness and major personality factors. Psychological Reports, 84(2), 497-500. https://doi.org/10.2466/pr0.1999.84.2.497

Rime, B. (1999). Expressing emotion, physical health, and emotional relief: A cognitive-social perspective. Advances in Mind-Body Medicine, 15, 175-179.

Rime, B., \& Zech, E. (2001). The social sharing of emotion: Interpersonal and collective dimensions. Boletin de Psicologia, 70, 97-108. Retrieved from http://hdl.handle.net/2078.1/92733

Satıc1, S.A.(2016). Psychological vulnerability, resilience, and subjective well-being: The mediating role of hope. Personality and Individual Differences, 102, 68-73. https://doi.org/10.1016/j.paid.2016.06.057

Schroevers, M. J., Helgeson, V. S., Sanderman, R., \& Ranchor, A. V. (2010). Type of social support matters for prediction of posttraumatic growth among cancer survivors. Psychooncology, 19(1), 46-53. https://doi.org/10.1002/pon.1501

Seligman, M. E. P. (2002). Authentic happiness: Using the new positive psychology to realize your potential for lasting fulfillment. New York, NY, US: Free Press.

Singh, K., \& Yu, X. N. (2010). Psychometric evaluation of the Connor-Davidson Resilience Scale (CD-RISC) in a sample of Indian students. Journal of Psychology, 1(1), 23-30. https://doi.org/10.1080/09764224.2010.11885442

Steptoe, A., Deaton, A., \& Stone, A. A. (2015). Subjective wellbeing, health, and ageing. The Lancet, 385(9968), 640-648. https://doi.org/10.1016/S0140-6736(13)61489-0

Tugade, M., \& Fredrickson, B. L. (2004). Resilient individuals use positive emotions to bounce back from negative emotional experiences. Journal of Personality and Social Psychology, 86(2), 320-333. https://doi.org/10.1037/0022-3514.86.2.320

Tuzgöl-Dost, M. (2005). Developing a subjective well-being scale validity and reliability studies. Turkish Psychological Counseling and Guidance Journal, 23, 103-111. Retrieved from https://toad.edam.com.tr/sites/default/files/pdf/oznel-iyi-olus-olcegi-toad.pdf

Van Emmerik, A. A., Kamphuis, J. H., Hulsbosch, A. M., \& Emmelkamp, P. M. (2002). Single session debriefing after psychological trauma: A meta-analysis. The Lancet, 360(9335), 766-771. https://doi.org/10.1016/S0140-6736(02)09897-5

Vera-Villarroel, P., Urzua, A., Celis-Atenas, P. P. K., \& Silva, J. (2012). Evaluation of subjective well-being: Analysis of the satisfaction with life scale in Chilean population. Universitas Psychologica, 11(3), 719-727. https://doi.org/10.11144/Javeriana.upsy11-3.eswa

Waugh, C. E., Thompson, R. J., \& Gotlib, I. H. (2011). Flexible emotional responsiveness in trait resilience. Emotion, 11(5), 1059-1067. https://doi.org/10.1037/a0021786

Werner, E. E., \& Smith, R. S. (2001). Journeys from childhood to midlife: Risk, resilience, and recovery. Ithaca, NY: Cornell University Press.

Woods, V. (2005). Work-related musculoskeletal health and social support. Occupational Medicine, 55, 177.

Yıldırım, M., \& Belen, H. (2019). The role of resilience in the relationships between externality of happiness and subjective well-being and flourishing: A structural equation model approach. Journal of Positive Psychology and Wellbeing, 3(1), 62-76. Retrieved from http://www.journalppw.com/index.php/JPPW/article /view/85/43

Zech, E. (1998). Is it helpful to verbalize ones emotions? Gedrag and Gezondheid, 27, 42-47. Retrieved from https:/dial.uclouvain.be/pr/boreal/object/boreal\%3A92732/datastream/PDF_01/view

Zubair, A., Kamal, A., \& Artemeva, V. (2018). Mindfulness and resilience as predictors of subjective well-being among university students: A cross cultural perspective. Journal of Behavioural Sciences, 28(2), 1-19. Retrieved from http://pu.edu.pk/images/journal/doap/PDF-FILES/01_v28_2_18.pdf 


\section{Copyrights}

Copyright for this article is retained by the author(s), with first publication rights granted to the journal.

This is an open-access article distributed under the terms and conditions of the Creative Commons Attribution license (http://creativecommons.org/licenses/by/4.0/). 